\title{
An Electron Microscope and Biochemical Study of Neurospora crassa during Development
}

\author{
BY BARBARA WEISS* \\ Adolphus Busch III Laboratory of Molecular Biology, \\ Washington University, St Louis, Missouri, U.S.A.
}

(Received 30 October 1964)

\begin{abstract}
SUMMARY
Mitochondria isolated from protoplasts of conidia, young germinated conidia, and branched mycelia of Neurospora crassa, have an active oxidative phosphorylation system which showed no variation in the three stages of development studied; succinate dehydrogenase also did not alter. Cytochrome oxidase activity showed a marked increase at the time of conidial germination; this was not maintained during further growth. An electron microscope study of the conidia showed them to have complex mitochondria analogous to those seen in older mycelial hyphae. A large accumulation of lipid material and extensive vacuolization was observed in these conidia. A rudimentary reticular system with numerous ribosomes lying free in this membrane system were observed. Macroconidia were usually multinucleate; up to 10 nuclei were observed. The outer conidial wall was completely digested by snail extract (Helix pomatia digestive juice) and was structurally identical with that of the hyphae as seen with the fixation and embedding conditions used.
\end{abstract}

\section{INTRODUCTION}

Neurospora crassa undergoes different morphological changes depending on the conditions under which it is cultivated. Studies which attempted to correlate progressive alterations in enzyme activities with these morphological transformations in wild-type Neurospora have been made by several workers. Zalokar (1959) examined the effects of hyphal morphology and growth stage on four different enzymes (succinate dehydrogenase, aldolase, $\beta$-galactosidase, tryptophan synthetase). Turian (1962) studied the process of conidiation and suggested that an alteration in the concentration of succinate dehydrogenase and isocitrate lyase might occur during conidiogenesis. It seems clear from these studies with Neurospora, and from the work of Yotsuyanagi (1962) with yeast, that significant changes in enzyme activities associated with oxidative metabolism might accompany the processes of biological differentiation.

In the present work an attempt was made to examine several oxidative enzymes unequivocally bound to mitochondrial membranes at the critical stages of conidiation and conidial germination in wild-type Neurospora crassa; the phosphorylating function of the mitochondria was also examined. An electron microscope study was made to correlate where possible the biochemical results with the morphological

* Present address: Institut de Botanique Generale, Université de Genève, Genève, Switzerland. 
changes. Attention was focused on the structure of the conidia, since several studies on the structure of the hyphae of wild-type Neurospora were available for comparison.

\section{METHODS}

Growth conditions. Wild-type Neurospora crassa, strain Chilton $a$, was grown at room temperature $\left(23^{\circ}\right)$ on $500 \mathrm{ml}$. solid medium in $2600 \mathrm{ml}$. Fernbach flasks. The medium contained (g./1.): 10 , sucrose; 5 , yeast extract; 25 , agar; 5 , ammonium tartrate; $1 \cdot 0, \mathrm{NH}_{4} \mathrm{NO}_{3} ; 1 \cdot 0, \mathrm{KH}_{2} \mathrm{PO}_{4} ; 0 \cdot 5, \mathrm{MgSO}_{4} ; 0 \cdot 1, \mathrm{NaCl} ; 0 \cdot 1, \mathrm{CaCl}_{2}$. The salts were at the concentration of Fries no. 3 solution (Ryan, Beadle \& Tatum, 1943). To ensure adequate aeration, the flasks were covered with thin layers of cottonwool between several layers of cheese cloth. Cultures were harvested 7-10 days after inoculation by washing the hyphae and conidia from the agar surface with cold sterile distilled water. Conidia were separated from hyphae by filtration through glass wool which removed all vegetative filaments.

To obtain a fairly uniform population of young germinated organisms, conidia isolated in the above manner were added to $6 \mathrm{l}$. Erlenmeyer flasks containing $\mathbf{3 . 5} \mathrm{l}$. liquid medium. The absolute number of conidia added to this volume was usually about $1.8 \times 10^{10}$. Cultures were vigorously aerated at room temperature by bubbling filtered (cottonwool) air into the medium. To prevent clumping and the formation of mats along the walls of the flask, the medium was stirred with a magnetic stirrer thermally insulated from the flask by a layer of 'rock wool'. To prevent foaming, a silicon anti-foaming agent (Dow Corning antifoam A spray) was sprayed into each flask before autoclaving.

Under these conditions, germination began within $2 \mathrm{hr}$; the total number of germinated conidia increased at a linear rate for about $8 \mathrm{hr}$, at which time maximum germination (90\%) was reached. After $10 \mathrm{hr}$, the majority of organisms had wellformed unbranched germination tubes. When the growth period was extended to 15-16 hr, the hyphae developed into very long and extensively branched mycelial systems.

Preparation of protoplasts from conidia and young germinated conidia. The procedure described by Kinsky (1962) was modified to obtain protoplasts from conidia and germinated conidia in yields large enough for biochemical and ultrastructural analyses on the mitochondria isolated from them. Conidia washed from the surface of one Fernbach flask were separated from hyphal fragments by filtration through glass wool and washed several times with $0 \cdot 05 \mathrm{M}$-sodium phosphate ( $\mathrm{pH} \mathrm{6.8)}$. Germinated conidia were collected on a Buchner funnel and washed similarly. The entire yield (about 2-3 g. wet wt. of organism) was suspended in a $50 \mathrm{ml}$. Erlenmeyer flask with cottonwool plug in the following incubation mixture: $18 \mathrm{ml}$. $0.05 \mathrm{M}$-sodium phosphate ( $\mathrm{pH} \mathrm{6.8)}$ containing glutathione $(0.05-0.1 \mathrm{M}$ ) and sucrose $(0 \cdot 44 \mathrm{M}) ; 2 \mathrm{ml}$. Helix pomatia digestive juice preparation. (Suc digestif du $\boldsymbol{H}$. pomatia bought from L'Industrie biologique française, Gennevilliers, Seine, France; supernatant fluid from $2 \mathrm{ml}$. centrifuged for $30 \mathrm{~min}$. and $8200 \mathrm{~g}$ in 856 head of International centrifuge). The flask was placed in a water bath at $30^{\circ}$ and shaken gently for 10-15 hr. Conidia and protoplasts were removed from the incubation mixture by low-speed centrifugation $(5 \mathrm{~min}$. at $900 \mathrm{~g}$ ) and washed 2-3 times with tris $+\mathrm{HCl}(\mathrm{pH} 7 \cdot 4)$ containing sucrose $(0 \cdot 44 \mathrm{M})$. 


\section{Disruption procedures and isolation of mitochondria}

Mitochondria from protoplasts. Washed protoplasts were broken gently in a glass homogenizer. Whole organisms and debris were removed by centrifugation at about $900 \mathrm{~g}$ for $5 \mathrm{~min}$. periods. Mitochondria were sedimented from the resulting cellfree homogenate by centrifugation at $18,600 \mathrm{~g}$ for $20 \mathrm{~min}$.

Mitochondria from conidia. Conidia and germinated conidia were collected on a Buchner funnel with two to three layers of Whatman no. 1 filter paper. The resulting mat of organisms was washed, weighed and placed in a chilled porcelain mortar with washed and ignited sea-sand equal to 2-3 times the wet weight of the mat. The mixture was ground for about $10 \mathrm{~min}$. in the cold with the addition of a small amount of tris/ $\mathrm{HCl}$ buffer $(0.05 \mathrm{M}, \mathrm{pH} 7 \cdot 4)$ containing $0.44 \mathrm{M}$-sucrose. The sand was partially removed by allowing it to settle in the cold for a few minutes. The remaining whole organisms, debris, and sand were removed by centrifugation at $900 \mathrm{~g}$ for two $5 \mathrm{~min}$. periods. Mitochondria were separated from the homogenate by sedimentation at $18,000 \mathrm{~g}$ for $20 \mathrm{~min}$.

Mitochondrial suspensions were either used at once or frozen rapidly in liquid nitrogen and stored for short times (1-2 days) before use.

Enzyme assay methods. (1) Succinate dehydrogenase was assayed by the phenazine methosulphate (PMS) procedure of Singer \& Kearney (1957) at $37^{\circ}$ in microWarburg vessels (capacity about $7 \mathrm{ml}$.). Oxygen uptake was measured at a series of dye concentrations.

(2) Cytochrome oxidase assay. Oxygen uptake in the presence of non-enzymically reduced cytochrome $c$ was measured by the method of Slater (1949); the reducing agent was ascorbic acid, and manometry was at $37^{\circ}$ in double side-arm Warburg vessels (capacity about $15 \mathrm{ml}$.).

(3) Oxidative phosphorylation. A modification of the method of Hunter (1955) was used. To the main compartment of micro-Warburg vessels were added the following reagents : $20 \mu$ mole, tris $+\mathrm{HCl}(\mathrm{pH} 7 \cdot 4)$; $10 \mu$ mole $\mathrm{KH}_{2} \mathrm{PO}_{4}(\mathrm{pH} 7 \cdot 6)$; $3 \mu$ mole ADP; $5 \mu$ mole $\mathrm{MgCl}_{2} ; 3 \mathrm{mg}$. bovine serum albumin; $20 \mu$ mole sodium succinate ( $\mathrm{pH} \mathrm{7 \cdot 4}$ ); enzyme in buffered sucrose; distilled water to a total volume of $\mathbf{1 . 6} \mathrm{ml}$. To the side arm was added $90 \mu$ mole glucose and $0.5 \mathrm{mg}$. hexokinase. The centre well contained $0.2 \mathrm{ml} .10 \% \mathrm{KOH}$ and a filter-paper wick. The reaction mixture was equilibrated at $30^{\circ}$ for $7 \mathrm{~min}$., after which the hexokinase + glucose mixture was tipped in. Oxygen uptake was measured every $5 \mathrm{~min}$. for $30 \mathrm{~min}$. The reaction was stopped by adding $0.2 \mathrm{ml} .30 \%(\mathrm{w} / \mathrm{v})$ trichloroacetic acid solution. In each assay at least two controls were deproteinized immediately after equilibration to provide zero-time phosphate concentrations. Phosphorylation was measured as the disappearance of inorganic phosphate from the reaction mixture by the method of Fiske \& SubbaRow (Lindberg \& Ernster, 1956).

Protein was measured by the method of Lowry, Rosebrough, Farr \& Randall (1951), with a standard curve obtained for human serum albumin.

Electron microscope techniques. Four fixatives were used: (1) potassium permanganate, $4 \%(\mathrm{w} / \mathrm{v})$ in distilled water; $(2)$ osmium tetroxide, $1 \%(\mathrm{w} / \mathrm{v})$ in Palade's veronal + acetate buffer adjusted to $\mathrm{pH} 7 \cdot 3-7 \cdot 5$ with $0 \cdot 1 \mathrm{M}-\mathrm{HCl} ;(3)$ glutaraldehyde, $5 \%(\mathrm{w} / \mathrm{v})$ in $0.05 \mathrm{M}$-sodium phosphate $(\mathrm{pH} 7 \cdot 0-7 \cdot 2) ;(4)$ formalin, $10 \%(\mathrm{v} / \mathrm{v})$ in $0.05 \mathrm{M}$-sodium phosphate $(\mathrm{pH} 7 \cdot 0-7 \cdot 2)$. For most experiments, particularly those 
with isolated particles or protoplasts, $0.44 \mathrm{M}$-sucrose was added to all fixative solutions.

Dehydration was always done through a graded series of ethanol + water mixtures.

For embedding a 9/1 (by volume) mixture of butyl-and methyl-methacrylate was used. Uranyl acetate $(0.035 \%, \mathrm{w} / \mathrm{v})$ was routinely added to the monomer mixture, as suggested by Shatkin \& Tatum (1959).

The following fixation, dehydration and embedding schedule was used with protoplasts and mitochondrial pellets: (1) Fix in glutaraldehyde or formalin for $2 \mathrm{hr}$ at $4^{\circ}$. (2) Wash twice with $0 \cdot 05 \mathrm{M}$-phosphate buffer $(\mathrm{pH} 7 \cdot 4)$ containing $0 \cdot 44 \mathrm{M}$ sucrose. (3) Let stand overnight at $4^{\circ}$ in buffered sucrose. (4) Post-fix in osmium tetroxide for $2 \mathrm{hr}$ at $4^{\circ}$. (5) Wash in buffered sucrose. (6) Dehydrate through a graded series of ethanol + water mixtures. (7) Infiltrate with methacrylate. (8) Polymerize by transferring samples to gelatin capsules containing partially polymerized methacrylate that is quite viscous. Allow further polymerization to proceed very slowly at room temperature or at $37^{\circ}$ for $1-3$ days.

Blocks were sectioned with a Porter-Blum manual ultramicrotome. Dried sections were stained with uranyl nitrate (saturated solution in distilled water) for $2-5 \mathrm{hr}$. All preparations were examined and photographed with a Siemens Elmiskop I electron microscope at magnification $\times 8000$ or $\times 40,000$ and a beam potential of $80 \mathrm{kV}$.

\section{RESULTS}

\section{The succinate dehydrogenase system and oxidative phosphorylation}

To obtain phosphorylation of ADP coupled to oxidation of succinate it was essential that the mitochondria were relatively intact. The method finally adopted involved the production of protoplasts from hyphae or conidia and their subsequent lysis either by homogenization or osmotic shock. With this method, yields of mitochondrial protein/flask-yield of conidia were low (5-15 mg./flask) but sufficient for enzymic and ultrastructural studies. Table 1 gives $\mathrm{P} / \mathrm{O}$ ratios for mitochondria from organisms of different stages prepared by the protoplast method and by grinding with sand. Preparations by the latter method gave erratic results with unfractionated suspensions of mitochondria; the $\mathrm{P} / \mathrm{O}$ ratios were usually less than one and often not measurable at all. With mitochondria isolated from protoplasts, the $\mathbf{P} / \mathbf{O}$ ratios were consistently greater than one.

\section{Succinate dehydrogenase activity}

Succinate dehydrogenase activity was determined in isolated mitochondria from the three stages of growth; $\mathrm{pH} 7 \cdot 6$ was optimal in these assays. All assays were done with a series of different phenazine methosulphate concentrations, and maximum velocities were calculated by the Lineweaver-Burk double reciprocal method. Mitochondria which had been frozen in liquid nitrogen and stored for 1-3 days at $-20^{\circ}$ retained full dehydrogenase activity. For a given stage, the mitochondria prepared by grinding with sand or by protoplast lysis showed no significant differences in enzyme activity. The data in Table 2 indicate that the specific activity of succinate dehydrogenase did not differ appreciably in the three stages of growth examined. 
Table 1. Phosphorylative ability of mitochondria prepared from cells at different stages of development and by different methods of isolation

\begin{tabular}{|c|c|c|c|c|}
\hline \multirow{2}{*}{$\begin{array}{l}\text { Stage of growth } \\
\text { Conidia }\end{array}$} & $\begin{array}{l}\text { Method of cell } \\
\text { breakage }\end{array}$ & $\begin{array}{l}\mathrm{P} / \mathrm{O} \\
\text { ratios }\end{array}$ & $\begin{array}{c}\mu \text { moles } \\
\mathbf{P}_{i} \text { per } \\
\mathbf{3 0} \text { min. }\end{array}$ & $\begin{array}{c}\mu \text { atoms } \\
\mathrm{O}_{2} \text { per } \\
30 \text { min. }\end{array}$ \\
\hline & Protoplast lysis & $1 \cdot 3$ & $5 \cdot 0$ & $3 \cdot 8$ \\
\hline \multirow[b]{2}{*}{$10 \mathrm{hr}$ culture } & Sea sand grinding & $\begin{array}{l}0 \cdot 3 \\
0 \cdot 6\end{array}$ & $\begin{array}{l}3 \cdot 2 \\
3 \cdot 5\end{array}$ & $\begin{array}{r}10 \cdot 4 \\
5 \cdot 5\end{array}$ \\
\hline & Protoplast lysis & $\begin{array}{l}1 \cdot 1 \\
1 \cdot 4 \\
1 \cdot 9\end{array}$ & $\begin{array}{l}0 \cdot 88 \\
2 \cdot 0 \\
2 \cdot 0\end{array}$ & $\begin{array}{l}0 \cdot 79 \\
1 \cdot 39 \\
1 \cdot 09\end{array}$ \\
\hline \multirow{3}{*}{$15 \mathrm{hr}$ culture } & Sea sand grinding & $0 \cdot 7$ & $3 \cdot 0$ & 4.5 \\
\hline & Protoplast lysis & - & - & 一 \\
\hline & Sea sand grinding & $\begin{array}{l}0.6 \\
0.9\end{array}$ & $\begin{array}{l}6 \cdot 0 \\
6 \cdot 9\end{array}$ & $\begin{array}{r}10 \cdot 6 \\
7 \cdot 4\end{array}$ \\
\hline
\end{tabular}

The reaction mixture consisted of $20 \mu$ mole tris $+\mathrm{HCl}, \mathrm{pH} 7 \cdot 4,10 \mu$ mole $\mathrm{KH}_{2} \mathrm{PO}_{4}, \mathrm{pH} 7 \cdot 6$, $3 \mu$ mole ADP, $5 \mu$ mole $\mathrm{MgCl}_{2}, 3 \mathrm{mg}$. bovine serum albumin, $20 \mu$ mole sodium succinate, $\mathrm{pH} 7 \cdot 4$, enzyme in buffered sucrose and distilled water to give a total fluid volume of $1.6 \mathrm{ml}$. To the side arm of each Warburg vessel was added $90 \mu$ mole glucose and $0.5 \mathrm{mg}$. hexokinase. The centre well was filled with $10 \% \mathrm{KOH}$. The reaction was run at $30^{\circ}$ and was rapidly terminated after $30 \mathrm{~min}$. by the addition of $30 \%$ trichloroacetic acid.

\section{Table 2. Succinic dehydrogenase activity as a function of growth}

The main compartment of each micro-Warburg flask contained in a total fluid volume of $2 \cdot 2 \mathrm{ml}$.: $60 \mu$ mole sodium succinate, pH 7.0, $150 \mu$ mole sodium phosphate buffer, $\mathrm{pH} 7 \cdot 6,3 \mu$ mole $\mathrm{KCN}$ adjusted to $\mathrm{pH} 8.0$ with $0.085 \mathrm{~N}-\mathrm{HCl}, 1.65 \mu$ mole $^{-\mathrm{CaCl}_{2}}$, enzyme (sufficient to give $30-60 \mathrm{~mm}^{3}$ oxygen uptake in $5 \mathrm{~min}$.). The $\mathrm{KCN}$ was added just before the vessels were attached to the manometers. Phenazine methosulphate (1-4 mg.) in distilled water was added last to each side arm to minimize exposure to light and air. After a 7 min. equilibration, the dye was tipped in, and readings taken 2 and 7 min. later. All assays were performed at $37^{\circ}$.

$\begin{array}{lc}\text { Stage of growth } & \begin{array}{c}\text { Specific activity } \\ \left(\mu \mathrm{l} . \mathrm{O}_{2} / \mathrm{mg} .\right. \\ \text { protein } / \mathrm{hr})\end{array} \\ \text { Conidia } & 940-1068 \\ 10 \mathrm{hr} \text { culture } & 801-1068 \\ 15 \mathrm{hr} \text { culture } & 940-1090\end{array}$

\section{Cytochrome oxidase activity}

In this assay, maximum velocities were determined by extrapolation to infinite substrate concentration. Assays were made with mitochondria isolated from the same stages of growth as used for succinate dehydrogenase measurements; usually dehydrogenase and oxidase assays were done on each mitochondrial preparation. The data given in Table 3 indicate that a marked increase in cytochrome oxidase activity occurred at the time of conidial germination. A five- to tenfold increase in activity was observed in newly-germinated organisms as compared with ungerminated conidia. This high activity was not maintained; in $14-15 \mathrm{hr}$ cultures, the activity was again at values only slightly higher than those for the conidia. 


\section{The ultrastructure of conidia of Neurospora crassa}

Initial attempts to study the fine structure of conidia after osmium fixation and methacrylate embedding met with limited success. There were two main difficulties : first, although the ribosomes were well fixed and stained with osmium, the membranous structures, mitochondria and endoplasmic reticulum particularly, were obscured by the enormous quantity of ribosomes present; secondly, polymerization in methacrylate resulted in extensive cell damage. Yotsuyanagi (1959), with yeast cells, had similar difficulties. Organisms fixed in unbuffered $4 \%(\mathrm{w} / \mathrm{v})$ $\mathrm{KMnO}_{4}$ (which had been shown by him to dissociate ribonucleoproteins in in vitro experiments; Yotsuyanagi, 1962) effectively removed the ribosomes and permitted

\section{Table 3. Cytochrome oxidase activity at different stages of growth}

Each vessel contained in a total volume of $3.2 \mathrm{ml}$ : $26.4 \mu$ mole ascorbate (adjusted to pH 7.0 with $\mathrm{NaOH}), 0.5-1.5 \times 10^{-5} \mathrm{M}$ cytochrome $c, 65 \mu$ mole sodium phosphate buffer, pH $7 \cdot 3$, enzyme and distilled water to volume. In each experiment, the maximum rate of oxygen uptake was corrected for autoxidation of ascorbate at each concentration of cytochrome $c$ assayed. The corrected rates for oxygen uptake were plotted as $1 / V_{\max }$ versus 1 /cytochrome $c$ concentration and extrapolated to infinite substrate concentration to give the values presented in the table.

$\begin{array}{cc} & \begin{array}{c}\text { Specific activity } \\ \left(\mu \mathrm{l} . \mathrm{O}_{2} / \mathrm{mg} .\right.\end{array} \\ \text { Stage of growth } & \text { protein } / \mathrm{hr} .) \\ \text { Conidia } & 274 \\ 10 \mathrm{hr} \text { culture } & 1890 \\ 15 \mathrm{hr} \text { culture } & 461\end{array}$

better visualization of the other cell components. When this method was used with Neurospora conidia, complete removal of the ribosomes was obtained; in fact, the only structures preserved with this strong oxidizing agent were membranous organelles (mitochondria, Golgi apparatus, endoplasmic reticulum; Luft, 1956). The organisms were almost devoid of lipid inclusions. The mitochondria of these organisms were in structure completely analogous to the mitochondria of higher plants and animals; they contained numerous cristae in long parallel arrays, and were often of extremely irregular amoeboid shape. The hypotonicity of the fixative solution undoubtedly was responsible for the swollen appearance of these particles.

All the organisms were surrounded by a thick outer wall. The centre of the organism was occupied by a large vacuole, either clear or filled with granular material; surrounding this vacuole was finely granular cytoplasm. The endoplasmic reticulum was rather sparse and rudimentary, and the presence of a Golgi apparatus is uncertain. Most organisms contained more than one nucleus, and forms with 4 to 6 nuclei were quite common. The nucleoplasm appeared made up of granular light and dense regions. However, because of the nature of the fixative, it is unlikely that the nuclear material was well preserved in these organisms. Pl. 1, figs. 1, 2, and Pl. 2, fig. 3, illustrate the features of $\mathrm{KMnO}_{4}$-fixed conidia described above.

Because of the probable removal of many constituents of the organisms by $\mathrm{KMnO}_{4}$ fixation, they were examined after fixation in other ways. Sabatini, Miller \& Barnett (1964) found that several mono- and di-aldehydes provided good morphological preservation of cellular structures in mammalian tissues, and did not impair enzyme activity. Fixation procedures were therefore adopted which used 
glutaraldehyde and formaldehyde as primary fixatives of conidia. Post-fixation in osmium was done to increase contrast; it was expected that the aldehydes would penetrate more rapidly than would osmium. To facilitate rapid fixation, conidia treated with the Helix pomatia enzyme preparation were used for this work.

The most striking feature of organisms fixed with formaldehyde or glutaraldehyde (as compared with $\mathrm{KMnO}_{4}$ fixation) was the increased complexity seen. Aldehydefixed protoplasts contained components not seen in $\mathrm{KMnO}_{4}$-fixed organisms, and those elements common to both showed greater structural variability (see Pl. 2, fig. 4; Pl. 3, fig. 5). These protoplasts contained numerous uniformly dense bodies, ranging from 0.12 to $1.0 \mu$, and probably lipid in composition. These bodies were not visible in $\mathrm{KMnO}_{4}$-fixed protoplasts. Another unique component was some very electron-dense material found only within vacuolar spaces (Pl. 2, fig. 4). This material was found as a diffuse amorphous mass or densely packed into round bodies which varied in size from 0.15 to $2.5 \mu$ (mean value of $0 \cdot 44 \mu$; 79 particles measured). Another prominent structure not seen in $\mathrm{KMnO}_{4}$-fixed organisms was a vesicular body of varying size and internal content, and limited by a single membrane. These structures often contained membranous material or small lipid-like droplets, and varied in size from 0.25 to $1.2 \mu$ (mean value $0.60 \mu ; 80$ particles measured). These particles were usually closely associated with lipid droplets and mitochondria (see Pl. 3, fig. 5). The mitochondria of these protoplasts showed greater variability in shape. Many dumbbell-shaped, hemispherical, and ring-shaped mitochondria were encountered (Pl. 2, fig. 4). The central space enclosed by the ring-shaped particles was usually less granular than the surrounding cytoplasm. The endoplasmic reticulum was almost undetectable in most of these organisms and the coarser granularity of the cytoplasm was probably due to the presence of many free ribosomes. The nucleus did not show the distinct heterogeneity of $\mathrm{KMnO}_{4}$-fixed nuclei, and had a granularity much like the cytoplasm outside it. Most of the nuclei showed a restricted dense aggregation which seemed to be polarized toward the nuclear membrane (Pl. 2, fig. 4). Most of the conidia examined lacked cell wall material or were covered with small remnants of cell wall. This probably means that the Helix pomatia enzyme preparation completely digested the cell wall of the conidium and did not merely weaken it at a few select points.

\section{DISCUSSION}

The succinate dehydrogenase system at three stages of development of conidia of Neurospora crassa.

In all experiments with the phenazine methosulphate assay system, the specific activity of succinate dehydrogenase was high in conidial mitochondria and did not change significantly in the three stages of growth from which the mitochondria were isolated. These results are at variance with those reported by Zalokar (1956) and Turian (1962). Zalokar reported a tenfold increase in succinate dehydrogenase during the first $8 \mathrm{hr}$ of growth, beginning with ungerminated conidia; Turian reported that the activity of this enzyme was significantly altered depending on growth conditions, and suggested a reciprocal correlation between succinate dehydrogenase activity and the conidiogenic capabilities of wild-type hyphae. It is believed that the succinate dehydrogenase assay used here is a specific one for this 
dehydrogenase alone and provides a more accurate measure of it than the methods used by Zalokar and Turian. Singer \& Kearney (1957) pointed out that the method used by Zalokar with methylene blue as electron acceptor depended on the presence of enzymes to catalyse the transfer of electrons from the reduced dehydrogenase to methylene blue. The method used by Turian measures succino-cytochrome $c$ reductase activity, and not the dehydrogenase alone. In the present work the electron acceptor used was phenazine methosulphate, which has been shown to react specifically with the primary dehydrogenase in both particulate and soluble preparations, regardless of their source. The discrepancy between the results reported here and those of Zalokar and Turian might be explained if the concentration of some other enzyme playing a role in the reduction of methylene blue and the transfer of electrons from succinate to cytochrome $c$ underwent change during morphogenesis, rather than the dehydrogenase itself. The growth medium also can profoundly affect the enzyme composition of the organism. The difference in the carbon and nitrogen source used in this work as compared with that used by Zalokar and Turian may also account for the different activities observed.

Cytochrome oxidase, which is localized within the same membranous framework as succinate dehydrogenase, varied independently of it during development of the conidia. The data indicate a five- to tenfold increase in activity, which seems to be maintained only for the short period of time covering conidial germination. Because germination could not be synchronized, $10 \mathrm{hr}$ cultures were at different stages in the formation of their germination tubes. Thus, the activities measured were for a heterogeneous population that ranged from newly germinated conidia to conidia whose initial germination had occurred 6-8 hr earlier. This would suggest that the increase in cytochrome oxidase activity observed in $10 \mathrm{hr}$ cultures would have been greater if germination had occurred simultaneously in all conidia.

With regard to the phosphorylating capacities of Neurospora mitochondria, consistent results were difficult to obtain and, therefore, comparisons between stages are somewhat hazardous. The data suggest that no difference in phosphorylating ability exists between conidia and germinated conidia. Thus, although there is evidence for alterations in the level of specific enzymes associated with the TCA cycle and electron transport, the overall activity of the succinic-oxidase system and the concomitant production of ATP remains high throughout growth.

\section{The ultrastructure of conidia and hyphae}

The ultrastructure of wild-type Neurospora crassa mycelia has been studied by Zalokar (1961) and Shatkin \& Tatum (1959). Comparison between the ultrastructure of hyphae and conidia indicates many similarities. The cell wall of conidia appears to be identical with that of the hyphae. Although the membranes of the endoplasmic reticulum may be associated with ribosomes in the conidia, the large number of these granules free in the cytoplasm suggests that the association is non-specific. Zalokar has shown that in centrifuged Neurospora hyphae the vesicles of the endoplasmic reticulum can be completely separated from the ribosomes, suggesting a weak association. The mitochondria of hyphae and conidia show about the same degree of internal complexity and are approximately the same size. In conidia about $10 \%$ of these particles are in ring- or dumbbell-shaped forms. The variability in the number of nuclei per conidium is in agreement with light-microscope obser- 
vations (Huebschman, 1952). Glutaraldehyde- and formaldehyde-fixed conidia have a uniform granular nucleoplasm with a single dense polarized region, the nucleolus. Nuclei of potassium permanganate-fixed conidia do not show this single dense region. The nucleoplasm is divided into several finely granular areas of low density containing fibrillar material. Both methods of fixation probably remove or alter substances within the nucleus. The two fixation procedures may be demonstrating different components or different phases of the nucleoplasm.

Both conidia and hyphae contained large vacuoles. Often these vacuoles were seen to contain large dense bodies of unknown composition. These highly vacuolated conidia may represent an advanced stage in the life of the conidium. Conidia began to form on aerial hyphae within 3 days after inoculation and cultures were harvested 7-10 days after the initiation of growth. Thus, the age of conidia in a given population at the time they were collected varied considerably and might account for the variation in structure seen in the electron microscope. The observation that cultures which were deep orange at the height of conidial formation began to become bleached after 10-15 days suggests that degenerative changes occurred as the spore population ages.

This research was carried out in the laboratory of Dr R. G. Hart, while the author was a U.S. Public Health Service Trainee under grant number T 1GM 714-06.

\section{REFERENCES}

Huebschman, C. (1952). A method for varying the average number of nuclei in the conidia of Neurospora crassa. Mycologia, 44, 599.

Hunter, F. E. Jr. (1955). Coupling of phosphorylation with oxidation. Meth. Enzymol. 2, 610.

KINsky, S. C. (1962). Effect of polyene antibiotics on protoplasts of Neurospora crassa. J. Bact. 83, 351.

Lindberg, O. \& Ernster, L. (1956). Determination of organic phosphorus compounds by phosphate analysis. Meth. biochem. Analysis, 3, 3.

Lowry, O. H., Rosebrough, N. J., Farr, A. L. \& Randall, R. J. (1951). Protein measurement with the Folin phenol reagent. J. biol. Chem. 193, 265.

Luft, J. H. (1956). Permanganate: a new fixative for electron microscopy. J. biophys. biochem. Cytol. 2, 799.

Ryan, F. J., Beadle, G. W. \& Tatum, E. L. (1943). The tube method of measuring the growth rate of Neurospora. Amer. J. Bot. 30, 784.

Sabatini, D., Miller, F. \& Barnett, R. (1964). Aldehyde fixation for morphological and enzyme histochemical studies with the electron microscope. J. Histochem. Cytochem. $12,57$.

Shatkin, A. J. \& TAtum, E. (1959). Electron microscopy of Neurospora crassa mycelia. J. biophys. biochem. Cytol. 6, 423.

Singer, T. P. \& Kearney, E. B. (1957). Determination of succinic dehydrogenase activity. Meth. biochem. Analysis, 4, 307.

Slater, E. C. (1949). The measurement of the cytochrome oxidase activity of enzyme preparations. Biochem. J. 44, 305.

Turins, G. (1962). Deficiences du metabolisme oxydatif et differenciation sexuelle chez Allomyces et Neurospora. Activité d'une DPN-deshydrogenase lactique chez Allomyces. Pathologia Microbiol. 23, 687.

Yotsuyanagi, M. Y. (1959). Étude au microscope electronique des coupes ultrafine de la levure. C. r. hebd. Séanc. Acad. Sci., Paris, 248, 274. 
Yotsuyanagi, M. Y. (1962). Étude sur le chondriome de la levure. I. Variation de l'ultrastructure du chondriome au cours du cycle de la croissance aerobie. J. Ultrastructure Res. 7, 121.

Zalokar, M. (1959). Enzyme activity and cell differentiation in Neurospora. Amer. J. Bot. 46, 555 .

Zalokar, M. (1961). Electron microscopy of centrifuged hyphae of Neurospora. $J$. biophys. biochem. Cytol. 9, 609.

\section{EXPLANATION OF PLATES}

\section{Plate 1}

Fig. 1. Section through a $\mathrm{KMnO}_{4}$-fixed, methacrylate-embedded conidium. Note the thick outer cell wall, sparse reticulum, and abundant mitochondria with typical inner cristae in long parallel arrays. A single nucleus with breaks in the nuclear membrane is evident. The overall fine granularity of the cytoplasm and intra-mitochondrial matrix is typical of these cells. $\times 22,000$.

Fig. 2. A $\mathrm{KMnO}_{4}$-fixed conidium showing the large central vacuole filled with granular material. Note the irregular shape of the mitochondria and the small array of densely stained membranes which may be comparable to the Golgi apparatus of higher plants. $\times 18,000$.

\section{Plate 2}

Fig. 3. Thin section through a $\mathrm{KMnO}_{4}$-fixed conidium illustrating the multinucleate nature of these cells. The typical biphasic composition of the nucleoplasm observed only in $\mathrm{KMnO}_{4}$-fixed cells is evident here. $\times 19,700$.

Fig. 4. A section through a glutaraldehyde-fixed conidial protoplast. Note the complete absence of a cell wall. The cytoplasm is more coarsely granular than in $\mathrm{KMnO}_{4}$-fixed cells. The nuclei also have the same coarse granularity. Four of them in this section show a polarized dense region, which is presumed to be the nucleolus. The ring, hemispheric and dumbbell-shaped mitochondria frequently encountered in wild-type conidia are clearly demonstrated, as are the lipid bodies and dense inclusions within vacuolar spaces. $\times 20,300$.

\section{Plate 3}

Fig. 5. A section of a glutaraldehyde-fixed protoplast of a wild-type conidium. Of particular interest is the large number of vesicles associated with lipid droplets and mitochondria. Two very large lipid bodies are prominent. Particles of this size are atypical. The dense cristae folds and irregularly shaped mitochondria contrast with the thin parallel cristae and regular elliptical shape of the mitochondria of $\mathrm{KMnO}_{4}$-fixed cells. Some remnants of the outer cell wall can be seen in this section. $\times 27,000$. 


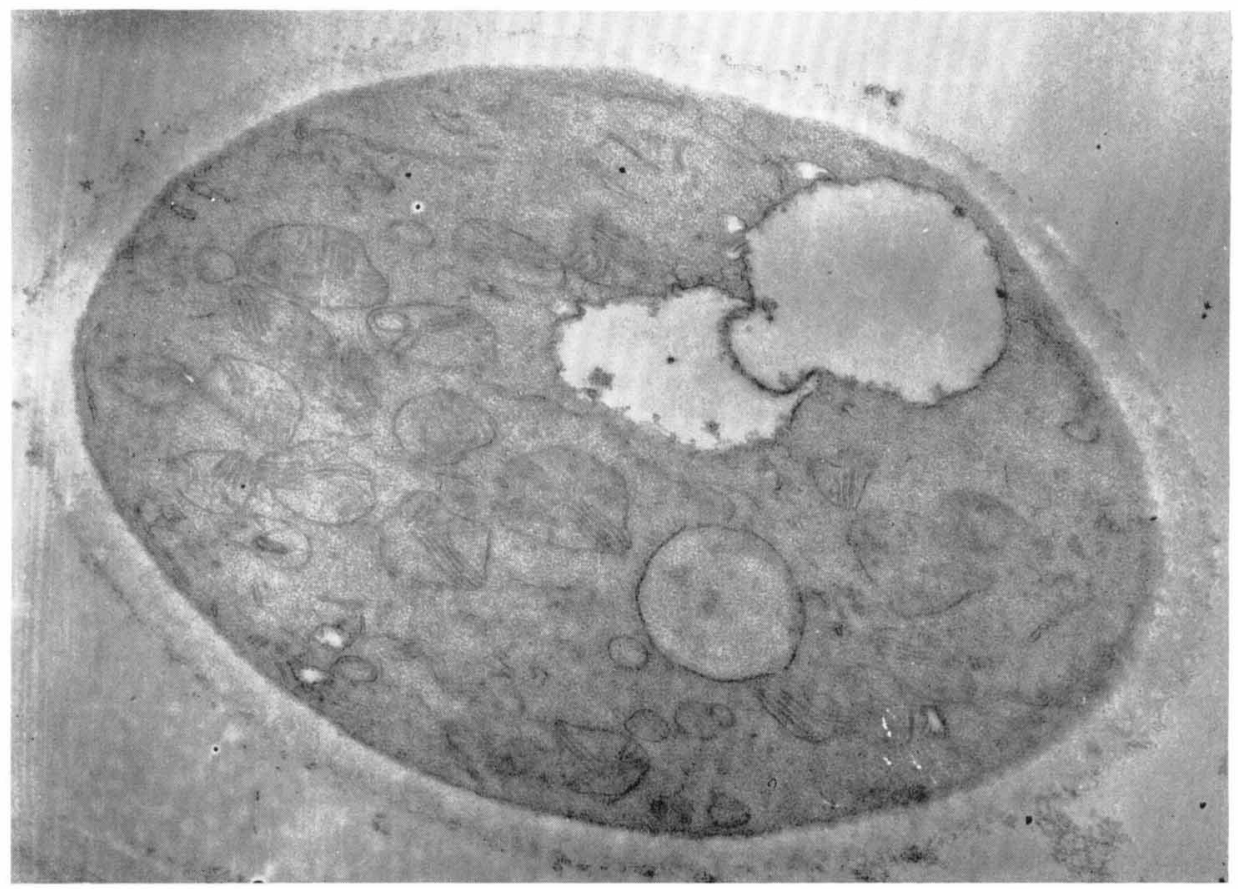

Fig. 1

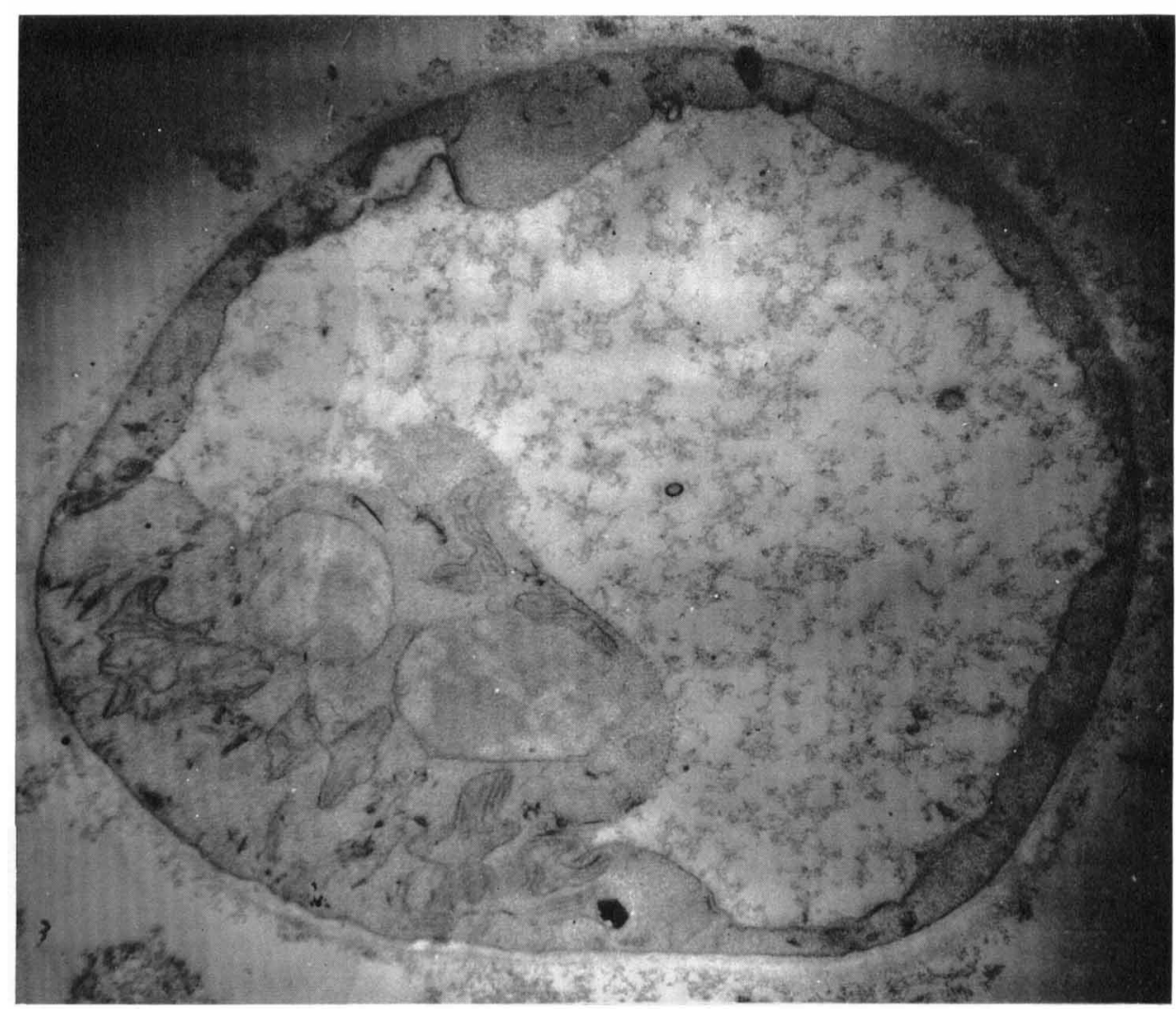

Fig. 2 


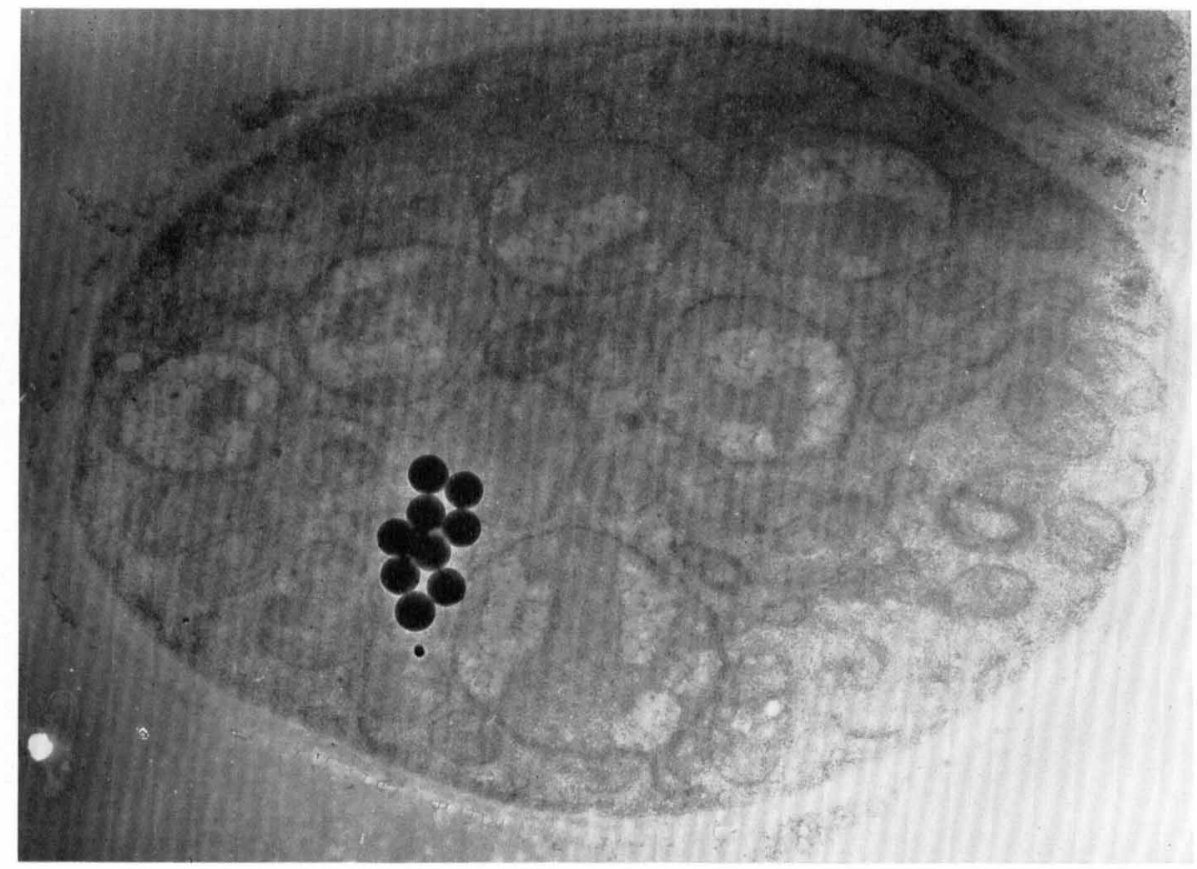

Fig. 3

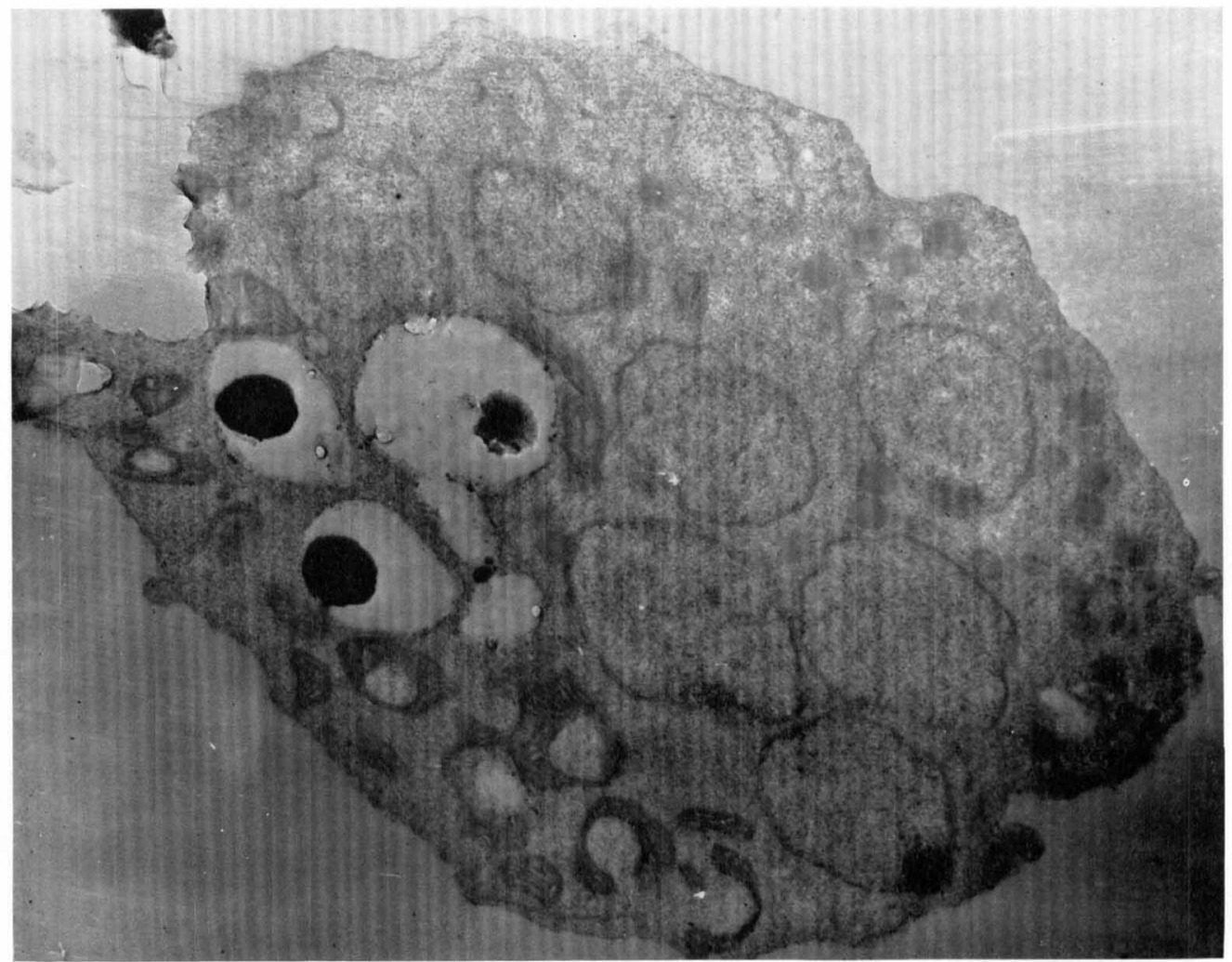




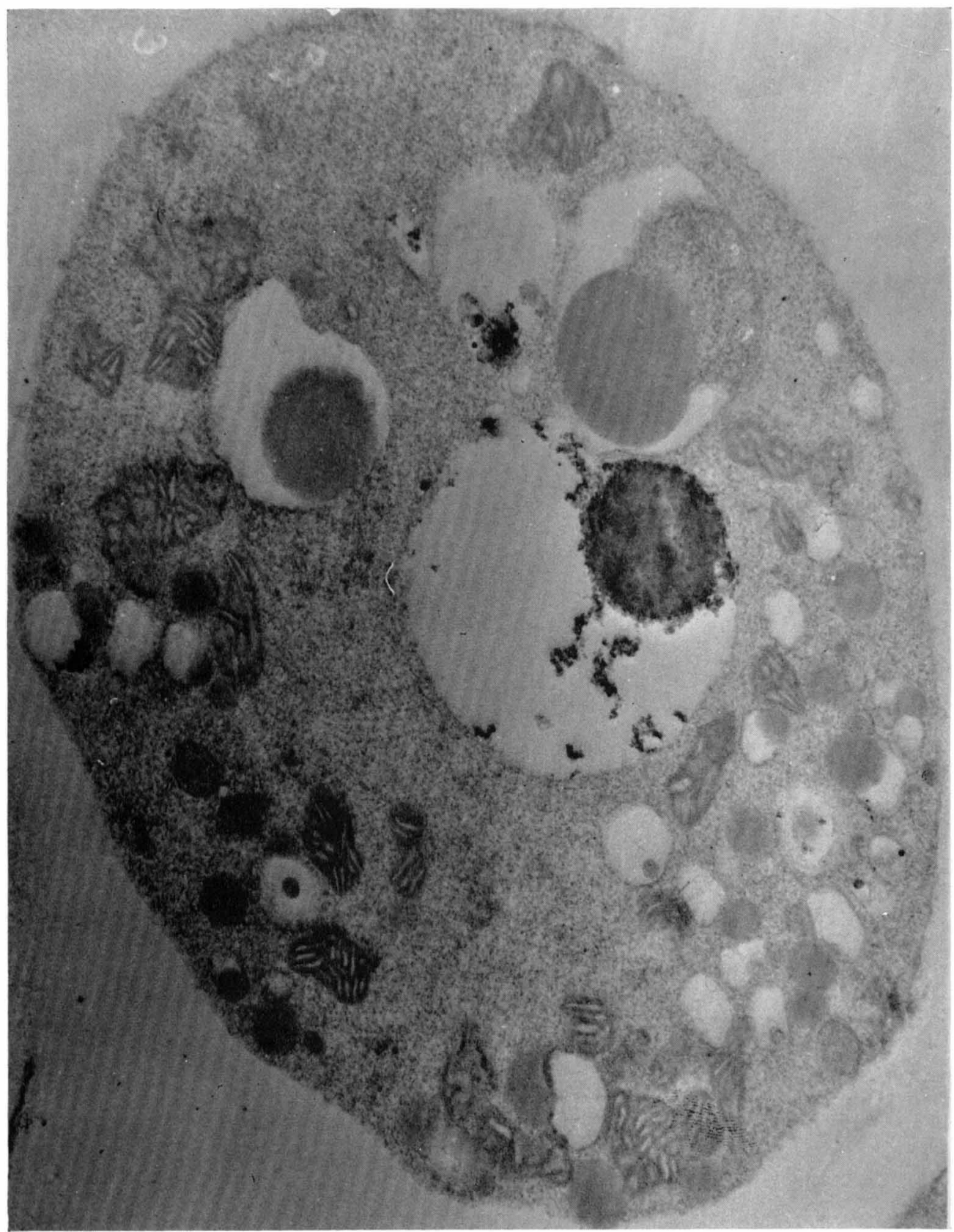

Fig. 5

B. WEISS 